\title{
MODEL ADOPSI UKM DI KUDUS TERHADAP E-COMMERCE
}

\author{
Muhammad Malik Hakim \\ Fakultas Teknik, Program Studi Teknik Informatika \\ Universitas Muria Kudus \\ Email: malik.hakim@umk.ac.id \\ Mukhamad Nurkamid \\ Fakultas Teknik, Program Studi Teknik Informatika \\ Universitas Muria Kudus \\ Email: muhammad.nurkamid@umk.ac.id
}

\begin{abstract}
ABSTRAK
Fungsi utama e-commerce saat ini adalah memungkinkan layanan pemasaran dan penjualan dapat dilakukan secara online di internet. Dengan e-commerce, pembeli dapat dengan mudah melihat produk unggulan dan bertransaksi sesuai dengan produk secara elektornik yang dipilihnya kapan dan dimana saja. Namun para pelaku UKM yang memiliki kemampuan dan fasilitas masih banyak yang belum memanfaatkan e-commerce secara optimal, yang berdampak pada kurang majunya perkembangan usahanya. Penelitian ini menjelaskan hubungan antar faktor yang berpengaruh terhadap pemanfaatan e-commerce oleh UKM Konvesi di Padurenan - Kabupaten Kudus. Penelitian dilakukan dengan Model UTAUT, dan selanjutnya dilakukan analisis terhadap variabel yang berpengaruh menggunakan metode SEM. Hasil penelitian menunjukkan bahwa adopsi e-commerce belum efektif dikarenakan UKM belum memiliki niat dan keyakinan yang tinggi terhadap manfaat penggunaan e-commerce; kurangnya faktor pengaruh sosial dari komunitas sesama UKM; serta kurangnya dukungan fasilitas baik sarana maupun prasarana dan tenaga ahli dari pihak pembina UKM terkait.
\end{abstract}

Kata kunci: UTAUT, UKM, e-commerce, pemasaran online, padurenan.

\section{ABSTRACT}

E-commerce is an online service-based application that enabling marketing and sales activities conducted on the Internet. With e-commerce, buyers can easily see and buy products they prefer anytime and anywhere. However, there are many SMEs that do not take the advantage of e-commerce optimally, resulting in less rapid advancement of its business development. This study explains the relationship among factors affecting the usage of e-commerce application systems, especially for Convection SME in Padurenan - Kudus. Study is conducted using UTAUT Model, and the data were analyzed by SEM Methods. The result shows that the adoption of SME in using e-commerce in Padurenan - Kudus has not been effective, because of some factors, such as they do not have the intention and confidence about the advantage of using e-commerce; the absence of social support from their own communities; and lack of infrastructure and expertise support from the government and other supporting institutions.

Keywords: UTAUT, SME, e-commerce, online marketing, padurenan.

\section{PENDAHULUAN}

Penetrasi pemanfaatan internet di Indonesia saat ini semakin tinggi, terlebih dengan semakin mudahnya masyarakat mengakses internet melalui berbagai sarana terutama sarana bergerak (mobile devices). Pemanfaatan internet yang semakin meluas tersebut menyebabkan perubahan paradigma dan cara hidup manusia, dari cara hidup dan kebiasaan yang berbasis manual menjadi berbasis elektronik. Hal ini terjadi pula dalam dunia bisnis / perdagangan dimana sebelum internet dimanfaatkan secara meluas, pada umumnya pelaku usaha menjalankan usahanya secara manual. Proses bisnis manual tersebut selanjutnya bertransformasi menjadi elektronik, sehingga berdagang yang dilakukan secara elektronik seringkali disebut sebagai electronic commerce (e-commerce). Perubahan proses bisnis dari manual ke elektronik dapat dilakukan melalui aplikasi e-commerce baik yang sudah tersedia maupun yang terhubung dengan internet secara online. Melalui aplikasi e-commerce, pelaku usaha dapat mengelektronikkan beberapa proses bisnis yang dilakukannya, antara lain promosi / pemasaran, transaksi, pencatatan / pembukuan, stok / inventori, dan lain-lain. Selain itu, proses bisnis yang telah bertransformasi dari manual menjadi elektronik dapat dengan mudah ditingkatkan menjadi online di internet, yang memiliki keuntungan antara lain tidak terikat oleh waktu, tempat, serta jarak. Keuntungan ini pada umumnya telah dinikmati oleh pelaku usaha besar, karena adanya faktor adaptasi dan adopsi teknologi yang cepat diantara pala pelaku usaha besar. 
UKM Padurenan sendiri memiliki peranan dan potensi strategis di dalam mengembangkan atau ikut memajukan bisnis di Kabupaten Kudus. Banyak sentra-sentra produktif lahir di desa ini. Jumlah UKM sampai dengan tahun 2015 terhimpun ada lebih kurang 200 UKM yang bergerak di bidang konveksi dan komoditaskomoditas yang lain, mulai dari komoditas baju, kerajinan dompet, telapak meja, kerudung, tutup tisu, tas dan kerajinan yang lainnya. Beberapa pelaku usaha kecil dan menengah (UKM) di Padurenan pada dasarnya dapat dan mampu mengikuti adaptasi dan adopsi terhadap teknologi seperti halnya yang dilakukan oleh para pelaku usaha besar. Namun karena adanya pemikiran menggunakan paradigma lama, maupun adanya kekurangpercayaan terhadap teknologi membuat transformasi usaha UKM menjadi terbatas. Contoh masalah yang ditemui antara lain kurangnya kesungguhan dan konsistensi dari pelaku UKM, meskipun mereka mampu menyediakan fasilitas yang dibutuhkan untuk menjalankan aplikasi e-commerce yang telah tersedia dan mampu mengoperasikannya. Masalah ini menjadi penghambat kemajuan usaha UKM di bisnis online sehingga diperlukan studi untuk mengetahui model adopsi terhadap aplikasi e-commerce pada UKM khususnya di desa Padurenan Kabupaten Kudus.

\section{METODOLOGI PENELITIAN}

Penelitian ini merupakan penelitian eksploratif deskriptif, yang mendeskripsikan (menggambarkan) fenomena mengenai model penerimaan dan penggunaan e-commerce oleh UKM konveksi/bordir di desa Padurenan Kudus. Dalam penelitian ini, digunakan metode kuantitatif korelasionaldengan UTAUT (Unified Theory of Acceptance and The Use of Technology) sebagai model utamanya. Pengambilan data dilakukan dengan pendekatan survey dalam bentuk pengisian kuesioner secara langsung oleh responden. Model UTAUT dimodifikasi pada variabel moderating yang mengasumsikan tidak ada pengaruh yang berasal dari jenis kelamin, umur, pengalaman penggunaan dan faktor kesukarelaan dalam penggunaan (adopsi) terhadap e-commerce.

\subsection{Metode Pengumpulan Data}

Dalam pengumpulan data, dilakukan teknik purposive sampling yang merupakan cara pengambilan sample kepada responden terpilih agar data yang dihasilkan lebih representatif dan akurat. Pada teknik sampling ini di pilih sebanyak 50 responden dari populasi UKM yang aktif. Kemudian reponden diminta utnuk mengisi kuisioner yang telah diberikan dan juga diminta untuk mengisi identititas diri seperti, nama UKM dan nama pengelola UKM. Setelah itu peneliti menjelaskan terlebih dahulu tentang maksud tujuan dilakukan pengisian angket serta prosedur pengisian angket. Sedangkan data sekunder diperoleh dari beberapa referensi seperti jurnal, artikel dan buku.

\subsection{Instrumen yang Digunakan}

Dalam penelitian ini, angket menjadi instrumen utama dengan lima variabel di dalamnya yang terdiri dari PE (Performance Expectancy), EE (Effort Expectancy), SI (Social Influence), FC (Faciliting Condition) dan BI (Behavioral Intention).

\subsection{Metode Pengolahan Data}

Pengolahan data dilakukan dengan teknik Structural Equation Model (SEM), yang membentuk hubungan antar variabel dalam persamaan regresi linier seacara bertingkat [1]. SEM merupakan salah satu bentuk penerapan statistika yang digunakan untuk menganalisis hubungan antar banyak variabel penelitian secara simultan (serempak). Adapun perangkat lunak yang digunakan adalah Warp-PLS 3.0 agar dapat menunjukkan model visualisasi hubungan variabel secara jelas [2].

\subsection{Metode Pengujian dan Analisa}

Pengujian instrument pada penelitian ini menggunakan dua bentuk pengujian, yaitu uji validitas dan uji reliabilitas. Uji validitas dilakukan dengan metode Pearson Product Moment, sedangkan uji reliabilitas menggunakan metode Cronbach Alpha. Adapun analisa data menggunakan metode statistika multivariat, yang menganalisis hubungan beberapa variabel-variabel dari Model UTAUT secara bersamaan. Selanjutnya hubungan variabel secara keseluruhan disusun dalam bentuk model struktural (structural model).

\subsection{UTAUT sebagai Model Adopsi Sistem Online}

UTAUT merupakan salah satu model adopsi terhadap teknologi yang merupakan pengembangan dari model adopsi sebelumnya, seperti TPB, TRA, dan TAM [3]. Beberapa model adopsi tersebut memiliki variabel konstruk yang saling berbeda, namun memiliki fungsi dan penggunaan yang saling 
beririsan antara satu model dengan model lainnya [4]. Pengembangan tersebut terutama pada variabel konstruk yang membentuknya, sehingga UTAUT dapat dikatakan sebagai model yang menyatukan variabel - variabel konstruk pada model penerimaan sebelumnya (unified). Di dalam Model UTAUT, terdapat dua variabel utama, yaitu variabel utama dan variabel moderating. Variabel utama berupa PE, EE, SI, dan FC, serta variabel moderating, yaitu jenis kelamin (gender), usia (age), pengalaman (experience), dan kesukarelaan (voluntariness of use) [5]. Gambar 1 menunjukkan Model UTAUT secara umum.

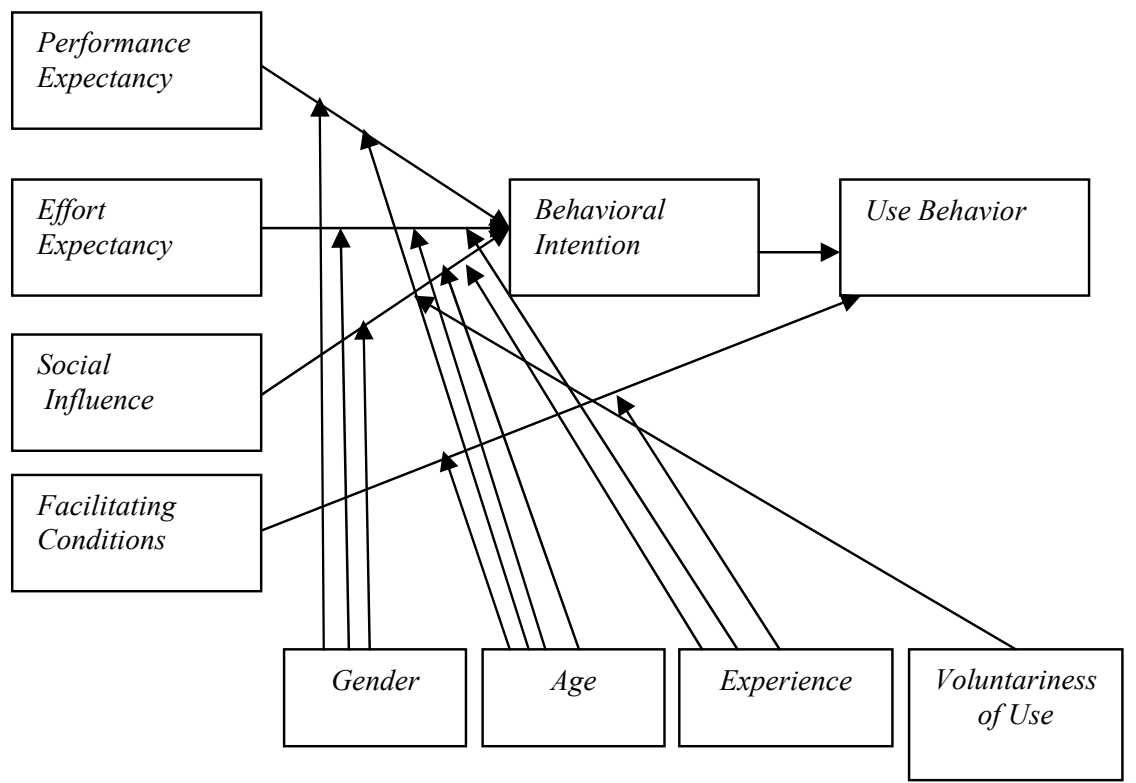

Gambar 1. Model UTAUT [5]

\subsection{Tinjauan Studi yang Relevan}

Penelitian mengenai adopsi teknologi oleh subyek tertentu telah banyak dilakukan, terutama terhadap penggunaan sistem informasi yang berjalan secara online di internet. Penerimaan pengguna terhadap sistem perpajakan online oleh Hakim [5], Wiyono [6], dan Schaupp dkk [7]. Selanjutnya, sistem perbankan elektronik (e-banking) telah diteliti model penerimaan penggunanya di beberapa negara oleh Gorecha [8], Liu [9], dan Yeow [10]. Sedangkan penerimaan pengguna terhadap e-commerce telah dilakukan oleh Nugroho [11] yang menggunakan Model TAM sebagai acuannya. Penelitian ini melakukan studi terhadap penerimaan e-commerce berbasis aplikasi yang berjalan secara online menggunakan Model UTAUT untuk memperkaya kajian mengenai analisis penerimaan dari sudut pandang metode yang berbeda dari beberapa penelitian sebelumnya.

\section{HASIL DAN PEMBAHASAN}

\subsection{Penyajian Data}

Penyajian data pada penelitian ini dilakukan dengan angket yang di distribusikan ke beberapa sampel UKM klaster konveksi/ bordir di Padurenan Kudus. Data angket yang berhasil diperoleh secara valid sebanyak 50 responden. Data tersebut disajikan dalam bentuk kuesioner yang terbagi ke dalam sembilan belas pernyataan. Adapun masing - masing pertanyaan dalam kuesioner yang dibagikan kepada responden adalah seperti pada Tabel 1 sampai Tabel 5.

Tabel 1. Daftar Pertanyaan untuk Variabel Performance Expectancy (PE) secara langsung

\begin{tabular}{cl}
\hline No & Pernyataan \\
\hline 1 & Menurut saya e-commerce sangat berguna dalam membantu menunjang bisnis saya \\
2 & Menurut saya e-commerce membuat transaksi menjadi lebih cepat \\
3 & Menurut saya, dengan e-commerce produktivitas bisnis akan meningkat \\
4 & Kedahan interaksi dengan pelanggan lebih mudah dengan $e$-commerce \\
\hline
\end{tabular}


Tabel 2. Daftar Pertanyaan untuk Variabel Effort Expectancy (PE)

\begin{tabular}{cl}
\hline No & \multicolumn{1}{c}{ Pernyataan } \\
\hline 1 & Menurut saya, sistem e-commerce mudah dimengerti dan difahami \\
2 & Menurut saya e-commerce mudah dioperasionalkan dalam bisnis saya sehari-hari \\
3 & Menurut saya aplikasi e-commerce mudah digunakan \\
4 & Menurut saya operasional aplikasi e-commerce mudah dipelajari \\
\hline
\end{tabular}

Tabel 3. Daftar Pertanyaan untuk Variabel Social Influence (SI)

\begin{tabular}{cl}
\hline No & \multicolumn{1}{c}{ Pernyataan } \\
\hline 1 & Pelanggan saya berpikir bahwa saya perlu menggunakan e-commerce \\
2 & Teman-teman pelaku UKM berpikir bahwa saya perlu menggunakan $e$-commerce \\
3 & Pendamping UKM mendorong untuk menggunakan $e$-commerce \\
4 & Komunitas / paguyuban UKM mendukung penggunaan $e$-commerce \\
\hline
\end{tabular}

Tabel 4. Daftar Pertanyaan untuk Variabel Facilitating Condition (FC)

\begin{tabular}{cl}
\hline No & \multicolumn{1}{c}{ Pernyataan } \\
\hline 1 & $\begin{array}{l}\text { Fasilitas untuk menjalankan } e \text {-commerce sudah saya miliki (komputer / laptop, } \\
\text { akses internet) }\end{array}$ \\
\hline 2 & $\begin{array}{l}\text { Saya tahu cara menggunakan e-commerce (menggunakan komputer, internet, dan e- } \\
\text { mail) }\end{array}$ \\
\hline 3 & Aplikasi e-commerce dapat dijalankan dengan fasilitas yang saya miliki. \\
\hline 4 & $\begin{array}{l}\text { Apabila mengalami kesulutan dalam menjalankan } e \text {-commerce, saya dapat meminta } \\
\text { bantuan kepada tim helpdesk yang ada }\end{array}$ \\
\hline
\end{tabular}

Tabel 5. Daftar Pertanyaan untuk Variabel Behavioral Intention (BI)

\begin{tabular}{cl}
\hline No & \multicolumn{1}{c}{ Pernyataan } \\
\hline 1 & Saya berniat menggunakan e-commerce dalam beberapa bulan ke depan \\
\hline 2 & $\begin{array}{l}\text { Saya akan mulai menggunakan e-commerce dalam beberapa bulan ke depan agar } \\
\text { segera mahir menggunakannya }\end{array}$ \\
\hline 3 & Saya berencana akan terus menggunakan e-commerce \\
\hline
\end{tabular}

\subsection{Pengujian Validitas dan Reliabilitas}

Berdasarkan hasil pengujian validitas Pearson Product Moment, untuk semua instrumen kuesioner diperoleh besarnya $r$ hasil perhitungan lebih besar daripada $r$ pada tabel. Hal ini menunjukkan keseluruhan butir-butir instrumen dalam kuesioner adalah valid. Selanjutnya, berdasarkan hasil perhitungan uji reliabilitas butir-butir instrumen dengan teknik Alpha Cronbach dan Product Momen diperoleh nilai sebesar 0.929 yang lebih besar daripada $r$ pada tabel sebesar 0,456 . Hal ini menandakan bahwa instrumen dalam kuesioner yang diedarkan kepada responden sudah reliabel.

\subsection{Analisis Hasil}

Berdasarkan pengolahan data dengan menggunakan SEM diketahui bahwa signifikansi pengaruh suatu variabel laten dengan variabel lainnya dalam penelitian ini adalah sebagai berikut ini. Pengaruh PE (Performance Expectancy) terhadap BI (Behavioral Intentions), SI (Social Influence) terhadap BI, BI terhadap USE (Use Behavior) maupun FC (Facilitating Conditions) terhadap USE adalah tidak signifikan, sedangkan pengaruh EE (Effort Expectancy) terhadap BI adalah signifikan positif. Pengaruh EE yang signifikan positif menunjukkan bahwa faktor persepsi yang positif terhadap e-commerce sangat berpengaruh pada penggunaan aplikasi e-commerce. Para pelaku UKM yang memiliki suatu gambaran bahwa e-commerce mudah digunakan dan mudah dipelajari menunjukkan bahwa hal ini akan membuat aplikasi e-commerce akan semakin dipergunakan secara terus menerus dan konsisten. Hal ini didasari oleh satu gambaran bahwa apabila mereka mahir (dapat) menggunakan aplikasi dan aplikasi e-commerce sendiri itu mudah dipelajari menjadi faktor utama yang membuat aplikasi e-commerce akan selalu dipergunakan sebagai sarana komunikasi.

Sedangkan mengenai kurang signifikannya pengaruh PE terhadap BI, hal ini menunjukkan bahwa para pelaku UKM masih belum memiliki keyakinan yang tinggi mengenai dampak positif (manfaat) 
penggunaan e-commerce bagi kinerja usaha mereka, karena selama ini pekerjaan promosi dan penjualan sebagian masih berbasis di rumah masing-masing. Hal ini dimungkinkan para pelaku belum mencoba menggunakan aplikasi e-commerce sehingga manfaatnya belum dapat dirasakan secara nyata. Oleh karena itu diperlukan beberapa program pelatihan maupun bimbingan teknis memanfaatkan aplikasi $e$ commerce untuk kepentingan usaha masing-masing. Sebagai dampak nyata dari kurangnya penggunaan e-commerce, pada penelitian ini terlihat bahwa SI tidak berpengaruh kepada BI secara signifikan. Hal ini dimungkinkan sebagai efek lanjutan dari kurangnya pemanfaatan aplikasi e-commerce oleh para pelaku usaha sehingga dukungan dan pengaruh dari pelaku UKM lain secara social masih sangat rendah, karena masih sedikit di antara mereka yang menggunakan aplikasi e-commerce.

Selain itu, pengaruh FC terhadap USE yang rendah juga dimungkinkan masih kurangnya dukungan dukungan fasilitas dan bantuan baik sarana maupun prasarana, terutama dalam menggunakan aplikasi $e$ commerce yang berjalan secara online. Kurangnya dukungan tersebut dapat dipenuhi dengan penyediaan fasilitas untuk mengakses aplikasi e-commerce, serta pendampingan terhadap pelaku UKM dalam menggunakan aplikasi e-commerce. Adapun mengenai pengaruh BI terhadap USE yang tidak signifikan, hal ini menunjukkan bahwa niat untuk menggunakan aplikasi e-commerce yang rendah akan menghasilkan keinginan yang rendah pula untuk menggunakan aplikasi e-commerce. Pengaruh yang tidak signifikan ini menunjukkan bahwa tingkat penggunaan dan keinginan untuk menggunakan aplikasi $e$ commerce di kalangan pelaku UKM di desa Padurenan masih cukup rendah. Sehingga masih diperlukan sosialisasi maupun pelatihan yang lebih memadai agar mampu mengubah persepsi pelaku UKM mengenai aplikasi e-commerce dan manfaatnya dalam operasional usaha sehari-hari.

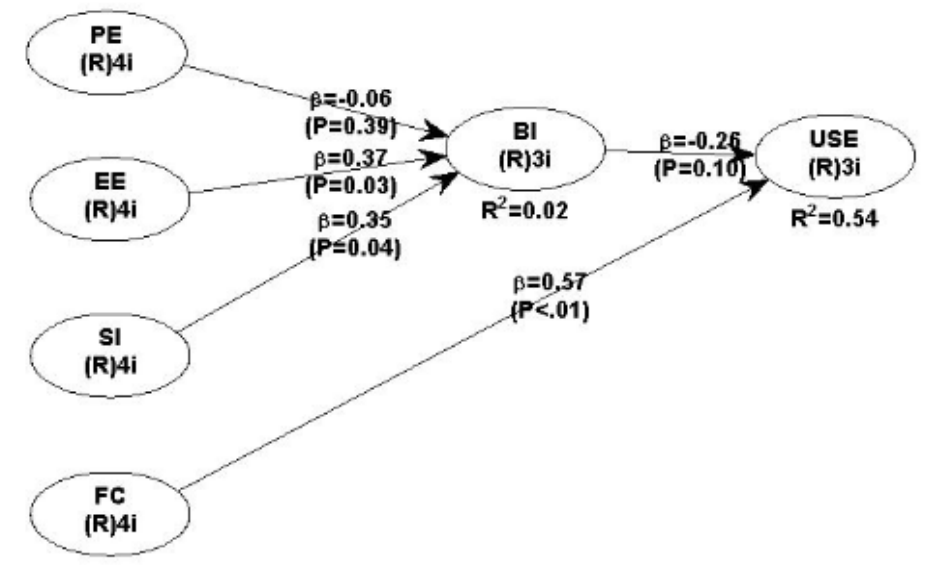

Gambar 2. Model Adopsi Obyek Penelitian

\section{KESIMPULAN}

Pemanfaatan e-commerce di UKM Padurenan Kudus terlihat belum efektif, hal ini dikarenakan pelaku UKM belum memiliki niat dan keyakinan yang tinggi terhadap manfaat penggunaan e-commerce; tidak adanya dukungan sosial dari komunitas UKM untuk menggunaan e-commerce; dan kurangnya dukungan fasilitas baik sarana maupun prasarana dan tenaga ahli dari pihak pemina UKM terkait.

\section{UCAPAN TERIMA KASIH}

Terima kasih disampaikan kepada Lemlit UMK (Lembaga Penelitian Universitas Muria Kudus) yang telah memberikan dukungan pendanaan dan fasilitas dalam pelaksanaan penelitian ini. Penelitian ini dilakukan dengan biaya yang bersumber dari Anggaran Pendapatan dan Belanja Universitas (APBU) Universitas Muria Kudus tahun akademik 2016/2017. 


\section{DAFTAR PUSTAKA}

[1] Hair, J. F., et. al. (2017). A Primer on Partial Least Squares Structural Equation Modeling (PLS-SEM), 2nd Edition. Thousand Oaks: Sage Publishing.

[2] Kock, N. (2010). Using WarpPLS in E-collaboration Studies: An Overview of Five Main Analysis Steps. International Journal of E-Collaboration 6. 4, 1-11. https://doi.org/10.4018/jec.2010100101

[3] Hakim, M. M. (2016). Analisis Model Penerimaan Pengguna Sistem Pelaporan Pajak Online. Jurnal Simetris 7. 1, 365-372. http:/jurnal.umk.ac.id/index.php/simet/article/view/526

[4] Azhari, R. dan Sari, I. (2008). Model - Model User Acceptance. Depok : Fakultas Ilmu Komputer Universitas Indonesia.

[5] Venkatesh, V. et. al. (2003). User Aceptance of Information Technology: Toward a Unified View. MIS Quarterly 27. 3, 425-78. http://misq.org/user-acceptance-of-information-technology-toward-a-unifiedview.html

[6] Wiyono, A. S. (2008). Evaluasi Perilaku Penerimaan Wajib Pajak terhadap Penggunaan E-Filling Sebagai Sarana Pelaporan Pajak Secara Online dan Realtime. Jurnal Riset Akuntansi Indonesia11. 2, 117-32.

[7] Schaupp, L. C., Carter, L., dan McBride, M. E. (2010) E-file Adoption: A Study of U.S. Taxpayers' Intentions. Computers in Human Behavior 26. 4, 636-44. http://dx.doi.org/10.1016/j.chb.2009.12.017

[8] Gorecha, A. (2005). Application of The Unified Theory of Acceptance and Use of Technology to Internet Banking. England: The University of Nottingham.

[9] Liu, G., Huang, S., Zhu, X. (2008). User Acceptance of Internet Banking in an Uncertain and Risky Environment. Proceedings of The 2008 International Conference on Risk Management and Engineering Management, 381-6. https://doi.org/10.1109/ICRMEM.2008.82

[10] Yeow, P. H. P., et. al. (2008). User Acceptance of Online Banking Service in Australia. Communication of The IBIMA 1. 191-7. http://ibimapublishing.com/articles/CIBIMA/2008/816627/

[11] Nugroho, M. A. (2009). Model Penerimaan E-commerce. Jurnal Pendidikan Akuntansi Indonesia (JPAI) 7. $2,46-55$. 